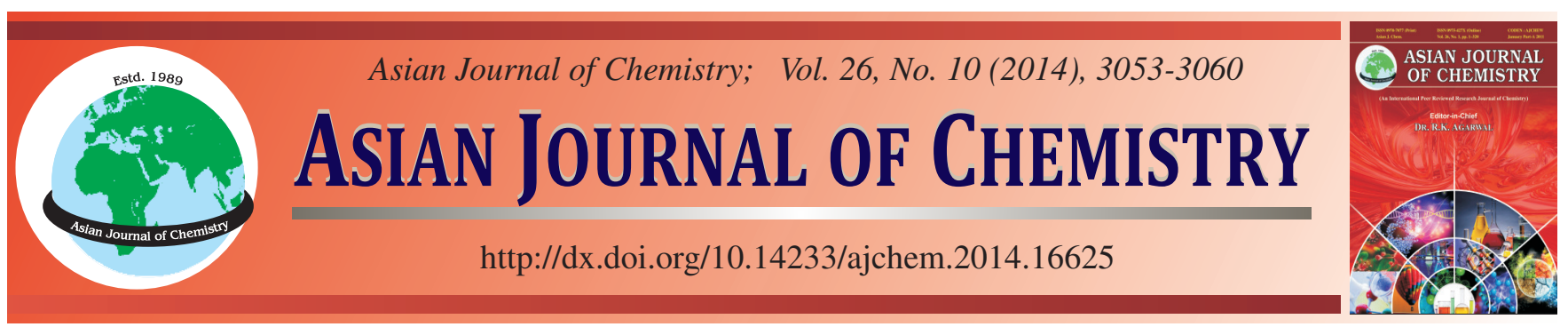

\title{
Thermodynamic Characterization on Surface of Iron Oxide Nanoparticles Prepared by Co-precipitation: An Inverse Gas Chromatography Application
}

\author{
SEDA BEyAZ ${ }^{1, *}$ and FERDANE KARAMAN ${ }^{2}$
}

${ }^{1}$ Balikesir University, Department of Chemistry, 10145 Cagis Campus, Balikesir, Turkey

${ }^{2}$ Yildiz Technical University, Department of Chemistry, 34220 Davutpasa Campus, Istanbul, Turkey

*Corresponding author: Fax: +90 266 6121215; Tel: +90 266 6121000; E-mail: sedacan@ balikesir.edu.tr; polymer22@ hotmail.com

Surface thermodynamics of magnetic particles are crucial for many applications. In this study, a series of magnetic iron oxide nanoparticles were synthesized by co-precipitation at room temperature varying iron salts and base concentrations. The retention times of several organic solvents on these iron oxide nanoparticles were obtained in the temperature range from 323 to $363 \mathrm{~K}$ by inverse gas chromatography at infinite dilution. The dispersive component of surface free energy, $\gamma_{s}{ }^{\mathrm{D}}$, thermodynamic parameters of adsorption (free energy, $\Delta \mathrm{G}^{\mathrm{SP}}$, enthalpy $\Delta \mathrm{H}^{\mathrm{SP}}$, entropy, $\Delta \mathrm{S}^{\mathrm{SP}}$ ) and the acid $\mathrm{K}_{\mathrm{A}}$ and base $\mathrm{K}_{\mathrm{D}}$ constants were calculated for iron oxide samples. It was found that $\gamma_{\mathrm{S}}{ }^{\mathrm{D}}$ values fluctuated between $36 \mathrm{~mJ} / \mathrm{m}^{2}$ and $20 \mathrm{~mJ} / \mathrm{m}^{2}$ for all of the samples and temperatures. It was seen that the values of $\mathrm{K}_{\mathrm{D}} / \mathrm{K}_{\mathrm{A}}$ were proportional with base concentration but inversely proportional with iron concentration. Hence it was arisen that the adsorption properties and acidbase contributions to the surface energy of iron oxide nanoparticles prepared by co-precipitation method altered considerably depending on the synthesis conditions. It can be said that the more effective surface modifications can be carried out adjusting synthesis conditions of iron oxide nanoparticles.

Keywords: Iron oxide nanoparticles, Inverse gas chromatography, Surface characterization, Co-precipitation.

\section{INTRODUCTION}

Magnetic iron oxide nanoparticles $\left(\mathrm{Fe}_{3} \mathrm{O}_{4}\right.$ or $\left.\gamma \mathrm{Fe}_{2} \mathrm{O}_{3}\right)$ can be used for numerous in vivo applications, such as MRI contrast enhancement, tissue repair, immunoassay, detoxification of biological fluids, hyperthermia, drug delivery and cell separation $^{1-6}$. These applications need peculiar surface coating of the magnetic nanoparticles, which has to be nontoxic and biocompatible and must also allow for a targetable delivery with particle localization in a specific area ${ }^{7}$. Thus the characterization of surface thermodynamics of the iron oxide nanoparticles is of vital importance in understanding their interface interactions with other substances for many applications ${ }^{8,9}$.

The synthesis methods used to prepare the nanoparticles determine the surface properties of the particles. Though there are miscellaneous chemical synthesis methods (such as thermal decomposition ${ }^{10}$, sol-gel ${ }^{11}$, microemulsion ${ }^{12}$ ), the most common method is still co-precipitation method ${ }^{13}$ because of simplicity, mass production and effortless surface modification for desired applications $\mathrm{s}^{14}$. This method consists of the precipitation of ferric and ferrous hydroxides by addition of a base $\left(e . g\right.$., $\mathrm{NH}_{4} \mathrm{OH}$ or $\mathrm{NaOH}$ ) to a solution of $\mathrm{Fe}(\mathrm{III})$ and $\mathrm{Fe}(\mathrm{II})$ salts (eqn. 1).

$$
2 \mathrm{Fe}^{3+}+\mathrm{Fe}^{2+}+8 \mathrm{OH}^{-} \longrightarrow \mathrm{Fe}_{3} \mathrm{O}_{4}+4 \mathrm{H}_{2} \mathrm{O}
$$

Depending on the stoichiometric mixture of ferrous and ferric salts in the aqueous medium and on other experimental conditions $[$ e.g., ionic strength and $\mathrm{pH}$ of the medium, presence of oxygen, injection fluxes, nature of the salts (perchlorates, chlorides, sulfates, or nitrates), temperature, nature and concentration of the alkali medium, or nature of the surfactant], iron oxide particles with suitable diameter, magnetic responsiveness and surface properties can be obtained ${ }^{15}$.

In aqueous systems, these iron oxides act as Lewis acids and adsorb/coordinate water or hydroxyl groups. The hydroxyl group at the surface may be coordinated to more than one Fe atom, so that, there are singly, doubly and triply coordinated $\mathrm{Fe}$ atoms. Further, two $\mathrm{OH}$ groups can coordinate to one iron atom. The coordination of hydroxyl groups and number of surface sites depends on the crystal structure and morphology of the iron oxide. This surface hydroxyl groups are, indeed, the reactive parts which can react with acid or base. It can be replaced by other organic or inorganic anions, adsorb protons or cations, release water by heating etc. ${ }^{16}$. Potentiometric titra$\operatorname{tion}^{17}$, spectroscopic methods (UV-visible, IR, XPS) ${ }^{16}$, contact angle measurements ${ }^{18,19}$ are among the techniques used to characterize the surface of these oxides e.g. its acidity, surface reactions, bonding coordination and adsorption properties. 
However, inverse gas chromatography (IGC) applications on characterization of magnetic iron oxide surfaces are highly new and have been carried out in recently ${ }^{20}$. Inverse gas chromatography has many advantages-simplicity, speed of data collection, accuracy and low operating costs and offers significant advantages over contact angle methods when comparing the surface nature of particulate samples ${ }^{21,22}$. Thus, it can be found many studies of inverse gas chromatography on the surface of inorganic particles ${ }^{23,24}$ such as kaolinite ${ }^{25,26}$ calcium carbonate $^{27,28}$ silica ${ }^{29,30}$ and metallic oxides such as magnesia ${ }^{31}$, zinc oxide ${ }^{32}$ in the literature. For iron oxides, there are also some studies standing out which are investigated commercially available products such as hematite ${ }^{33}$, goethite ${ }^{34}$, magnetite ${ }^{35}$. Besides, the surfaces of nanohematite and nanogoethite untreated and treated with poly(ethylene glycol) were examined by inverse gas chromatography in the study reported by Batko and Voelkel ${ }^{20}$. However no study was encountered in the literature related to an inverse gas chromatography application on the surface of the iron oxide nanoparticles prepared by coprecipitation method. Furthermore, though it has been assumed that the surface properties of iron oxide nanoparticles changes with the variables (e.g pH, concentration, temperature) of coprecipitation method ${ }^{15}$, an experimental study or confirmation is absence. That such information is of fundamental importance will be demonstrated in this paper by looking at samples synthesized with different experimental conditions.

In the study, a series of iron oxide nanoparticles were synthesized by co-precipitation method in the various concentrations of iron salts and base. By means of inverse gas chromatography technique, the surfaces of the particles were characterized with the quantities such as dispersive surface energy, adsorption enthalpy and entropy for alkanes, specific free enthalpy, enthalpy and entropy of adsorption for some polar solvents and finally acid-base constants of iron oxide nanoparticles. The results showed that desired surface properties can be gain in adjusting synthesis conditions of iron oxide nanoparticles for successful modifications.

\section{EXPERIMENTAL}

Ferric chloride hexahydrate $\left(\mathrm{FeCl}_{3} .6 \mathrm{H}_{2} \mathrm{O}\right.$, purity; > $\left.99 \%\right)$, aqueous ammonia $\left(\mathrm{NH}_{3}, 25 \%\right.$, w/w), nitric acid $\left(\mathrm{HNO}_{3}, 65 \%\right.$, $\mathrm{w} / \mathrm{v})$ were obtained from Merck. Ferrous chloride tetrahydrate $\left(\mathrm{FeCl}_{2} .4 \mathrm{H}_{2} \mathrm{O}\right.$, purity; $\left.99 \%\right)$ were purchased from Fluka. The solvents used in the inverse gas chromatography experiments, pentane (pen), $n$-hexane (hex), $n$-heptane (hep), $n$-octane (oct), nonane (non) as nonpolar solutes and dichlorometan ( $\mathrm{dcm})$, chloroform (cm), acetone (ace), tetrahydrofuran (thf), diethyl ether (et) as polar ones were supplied from Merck as analytical purity and used without further purification. The ChromosorbW (AW-DMCS treated, 80/100 mesh) were also supplied from Merck. Silane treated glass wool used to plug the ends of the column was obtained from Alltech Associates, Inc.

Synthesis of iron oxide nanoparticles: $50 \mathrm{~mL}$ iron salts solution which of $\mathrm{Fe}^{2+} / \mathrm{Fe}^{3+}$ mol ratios is $2 / 3$ was added into a $\mathrm{NH}_{4} \mathrm{OH}$ solution under stirring with $1500 \mathrm{rpm}$ and the reaction was carried out for $40 \mathrm{~min}$. Thereafter, the precipitated iron oxide was deposited with a magnet placed under the vessel of the solution and supernatant liquid was removed by decantation. In order to remove unreacted chemicals and byproducts that might be formed during the process; the precipitate was washed with bidistilled water. The names of the synthesized iron oxide nanoparticles and their synthesis conditions were listed in Table-1.

Dynamic light scattering: The studies were conducted using 90 Plus Particle Size Analyzer (Brookhaven Instruments) for hydrodynamic radius $(\mathrm{RH})$ and the polydispersity index $\left(\mathrm{PDI}=\mu^{2} / \Gamma^{2}\right)$ of iron oxide nanoparticles. Before measurements, the particles were suspended in water using $\mathrm{HNO}_{3}$. This sol was highly diluted up to become transparent and then was introduced into a thermostated scattering cell at $25^{\circ} \mathrm{C}$.

Inverse gas chromatography: A Hewlett-Packard 6890 Model series II gas chromatograph with a thermal conductivity detector was used to measure the retention time of the solutes in this study. The column was stainless steel tubing with 3.2 $\mathrm{mm}$ in o.d. and $0.5 \mathrm{~m}$ in length. Helium was used as the carrier gas at a flow rate of $3.7 \mathrm{~cm}^{3} / \mathrm{min}$. The columns were conditioned at $150{ }^{\circ} \mathrm{C}$ for $24 \mathrm{~h}$ under helium before all measurements. Solute vapours were injected manually at least in triplicate by a Hamilton gas-tight syringe. To achieve extreme dilution of the solutes, the syringe was purged as many times as necessary. Hold-up volume of columns was determined by injecting air. The retention times for each solute on iron oxide samples were measured at 323, 333, 343, 353 and $363 \mathrm{~K}$, except for sample $4 \mathrm{~K}$. This sample was studied at a wider temperature range between 313 and $383 \mathrm{~K}$ in order to see the transitions of iron oxide nanoparticles if any.

Preparation of sample columns: After the decantation of iron oxide nanoparticles under magnet, they were not dried and remained wet like slurry. Because the coating of dry nanoparticles (powder) on the surfaces of chromosorb homogeneously as single layer is highly difficult process due to agglomeration. The slurry of iron oxide was washed by bidistilled water until $\mathrm{pH}$ of the washing water is about 7 . Approximately $0.5 \mathrm{~g}$ of the slurry was taken and mixed with $1.37 \mathrm{~g}$ Chromosorb rather slowly. The mixture was dried under vacuum at $80{ }^{\circ} \mathrm{C}$ for $24 \mathrm{~h}$ to remove water and packed into

TABLE-1

EXPERIMENTAL CONDITIONS* AND THE SIZE PROPERTIES OF THE SYNTHESIZED IRON OXIDE NANOPARTICLES

\begin{tabular}{cccccc}
\hline Sample name & $\mathrm{Fe}^{2+}(\mathrm{mmol})$ & $\mathrm{Fe}^{3+}(\mathrm{mmol})$ & $\mathrm{NH}_{4} \mathrm{OH}(\mathrm{mmol})$ & $\mathrm{RH}^{\mathrm{a}}(\mathrm{nm})$ & $\mathrm{PDI}^{\mathrm{b}}$ \\
\hline $4 \mathrm{~K}$ & 40 & 60 & 288 & 10.7 & 0.159 \\
$3 \mathrm{~K}$ & 20 & 30 & 288 & 21.6 & 0.253 \\
2K & 10 & 15 & 288 & 0.243 \\
$1 \mathrm{~K}$ & 5 & 7.5 & 288 & 0.260 \\
1B & 10 & 15 & 444 & 23.3 & 0.167 \\
3B & 10 & & 62.7 & 0.294 \\
\hline *Total volume is $150 \mathrm{~mL},{ }^{a} \mathrm{RH}:$ Hydrodynamic radius, ${ }^{b}$ PDI: Polydispersity index &
\end{tabular}

*Total volume is $150 \mathrm{~mL},{ }^{a} \mathrm{RH}$ : Hydrodynamic radius, ${ }^{\text {b }} \mathrm{PDI}$ : Polydispersity index 
chromatography column. Meanwhile, the certain amount of the slurry was also dried to determine iron oxide amount in the slurry. Thus, the percentage of iron oxide/Chromosorb W was calculated around $8 \%$. Samples were freshly prepared and placed into the column to avoid oxidation ${ }^{36}$

Calculations and equations: The surface properties of a material under investigation are determined from net retention volume $\left(\mathrm{V}_{\mathrm{N}}\right)$ which is directly related to the net retention time of solute and flow rate of the carrier gas ${ }^{37}$. Retention volume $\left(\mathrm{V}_{\mathrm{N}}\right)$ can lead to the determination of the free enthalpy of adsorption, $\Delta \mathrm{G}_{\mathrm{A}}$ as given by the following expression ${ }^{38}$

$$
\Delta \mathrm{G}_{\mathrm{A}}=\mathrm{RT} \ln \left(\mathrm{V}_{\mathrm{N}}\right)+\mathrm{C}
$$

Here, $\mathrm{R}$ is the ideal gas constant, $\mathrm{T}$ is the absolute temperature of the column and $\mathrm{C}$ is a constant, depending on the reference state of adsorption. The $\Delta \mathrm{G}_{\mathrm{A}}$ is related to thermodynamic interaction of the solute with the solid surface and can be divided into two components

$$
\Delta \mathrm{G}_{\mathrm{A}}=\Delta \mathrm{G}^{\mathrm{D}}+\Delta \mathrm{G}^{\mathrm{SP}}
$$

Here, $\Delta \mathrm{G}^{\mathrm{D}}$ refers to dispersive interactions and $\Delta \mathrm{G}^{\mathrm{SP}}$ to specific interactions. In case of alkanes, $\Delta G_{A}$ is equal to $\Delta G^{D}$ corresponding to dispersive interactions. This relationship is used to calculate the dispersive surface energy of the solid $\left(\gamma_{\mathrm{S}}{ }^{\mathrm{D}}\right)$, using molecular areas $(\alpha)$ by Schultz et al. ${ }^{39}$.

$$
\mathrm{RT} \ln \left(\mathrm{V}_{\mathrm{N}}\right)=2 \mathrm{~N} \alpha \sqrt{\gamma_{\mathrm{L}}^{\mathrm{D}} \gamma_{\mathrm{S}}^{\mathrm{D}}}+\mathrm{C}
$$

where $\mathrm{N}$ is Avogadro's number, $\alpha$ is the area of interaction of the solute and $\gamma_{\mathrm{L}}{ }^{\mathrm{D}}$ is the dispersive component of the surface energy of the solute. Thus for a series of $n$-alkane solutes, a plot of $\mathrm{RT} \ln \left(\mathrm{V}_{\mathrm{N}}\right)$ against gives a linear line which slope is 2 $\mathrm{N} \alpha\left(\gamma_{\mathrm{S}}^{\mathrm{D}}\right)^{1 / 2}$ and $\gamma_{\mathrm{S}}^{\mathrm{D}}$ is determined.

$\gamma_{S}{ }^{\mathrm{D}}$ can also be determined by Dorris and Gray's method ${ }^{40}$ using retention times of $n$-alkanes and is given by eqn. 5 .

$$
\gamma_{\mathrm{s}}^{\mathrm{d}}=\frac{\left(-\Delta \mathrm{GH}_{2}\right)^{2}}{4 \mathrm{~N}^{2} \cdot \mathrm{a}_{\mathrm{CH}_{2} \cdot \gamma \mathrm{CH}_{2}}^{2}}
$$

where $\Delta \mathrm{G}_{\mathrm{CH}_{2}}$ is the slope of the straight line referred to as the "alkane line" and represents the free energy of a single $\mathrm{CH}_{2}$ group adsorption, $\alpha_{\mathrm{CH}_{2}}$ is the area occupied by a $\mathrm{CH}_{2}$ group $\left(0.06 \mathrm{~nm}^{2}\right.$, according to Gray) and $\gamma_{\mathrm{CH}_{2}}$ is the surface energy of a solid consisting of only methylene groups (e.g. polyethylene).

If a polar solute is injected into the column, both dispersive $\left(\Delta G^{D}\right)$ and specific interactions $\left(\Delta G^{\mathrm{SP}}\right)$ take place between the solute and the material in the column. The difference between the values of adsorption energy of polar solutes and the energy of $n$-alkane adsorption is a measure of the specific adsorption energy $\left(\Delta G^{S P}\right)$. An equation may be written for this procedure:

$$
-\Delta \mathrm{G}^{\mathrm{SP}}=\mathrm{RT} \ln \left(\frac{\mathrm{V}_{\mathrm{N}, \mathrm{n}}}{\mathrm{V}_{\mathrm{N}, \mathrm{ref}}}\right)
$$

where $V_{N, n}$ and $V_{N, \text { ref }}$ are the retention volume for the polar solute and the retention volume for the $n$-alkanes' reference line, respectively

By plotting $\Delta \mathrm{G}^{\mathrm{SP}}$ of polar solutes as a function of temperature, we can calculate the specific enthalpy $\left(\Delta \mathrm{H}^{\mathrm{SP}}\right)$ and the specific entropy $\left(\Delta \mathrm{S}^{\mathrm{SP}}\right)$ of adsorption from the following expression:

$$
\Delta \mathrm{G}^{\mathrm{SP}}=\Delta \mathrm{H}^{\mathrm{SP}}-\mathrm{T} \Delta \mathrm{S}^{\mathrm{SP}}
$$

Interactions between the solutes and the solid in the column can be considered as acid-base interactions ${ }^{41}$. Therefore, based on eqn. 8, the acceptor and donor interactions are estimated:

$$
-\Delta \mathrm{H}^{\mathrm{SP}}=\mathrm{K}_{\mathrm{A}} \mathrm{DN}+\mathrm{K}_{\mathrm{D}} \mathrm{AN}
$$

Here, DN and AN are Gutmann's donor and acceptor numbers of the solutes and parameters $\mathrm{K}_{\mathrm{A}}$ and $\mathrm{K}_{\mathrm{D}}$ characterize the degree of acidity of electron acceptors and the degree of basicity of electron donors of the solid surfaces, respectively. When plotting $\Delta \mathrm{H}^{\mathrm{SP}} / \mathrm{AN}$ versus DN/AN, generally, a straight line is achieved. The slope of the line gives $\mathrm{K}_{\mathrm{A}}$ and the intercept gives $K_{D}$. However $K_{D}$ is also determined from the slope of the graph of $\Delta \mathrm{H}^{\mathrm{SP}} / \mathrm{DN}$ versus $\mathrm{AN} / \mathrm{DN}$ since the slope of a plot is less affected by experimental error than the value of intercept.

In this study, the reference line of $n$-alkanes was obtained from their topology indices at the calculations of $\Delta \mathrm{G}^{\mathrm{SP}}, \Delta \mathrm{H}^{\mathrm{SP}}$ and $\Delta S^{S P}$. Additionally, it also was obtained from their surface areas and vapor pressures at the calculations of $\mathrm{K}_{\mathrm{A}}$ and $\mathrm{K}_{\mathrm{D}}$. The solute probe characteristics (DN, AN, $\left.\gamma_{\mathrm{L}}, \alpha, \chi_{\mathrm{t}}\right)^{34,42} \mathrm{used}$ in the calculations of the study were presented in Table-2.

TABLE-2

CHARACTERISTICS OF SOLUTE USED AT INVERSE GAS CHROMATOGRAPHY (IGC) EXPERIMENTS [34,42]

\begin{tabular}{lccccc}
\hline \multicolumn{1}{c}{ Solute } & $\begin{array}{c}\mathrm{a} \\
\left(\times 10^{-10} \mathrm{~m}^{2}\right)\end{array}$ & $\begin{array}{c}\gamma_{\mathrm{L}}^{\mathrm{D}} \\
\left(\mathrm{mJ} \mathrm{m}^{-2}\right)\end{array}$ & $\mathrm{DN}^{\#}$ & $\mathrm{AN}^{\#}$ & $\chi_{\mathrm{t}}$ \\
\hline$n$-pentane & 45.0 & 16.1 & 0 & 0 & 5.00 \\
$n$-hexane & 51.0 & 18.4 & 0 & 0 & 6.00 \\
$n$-heptane & 57.0 & 20.3 & 0 & 0 & 7.00 \\
$n$-octane & 62.8 & 21.3 & 0 & 0 & 8.00 \\
$n$-nonane & 69.0 & 22.7 & 0 & 0 & 9.00 \\
Dichloromethane & 31.5 & 27.6 & 3.0 & 13.5 & 2.58 \\
Chloroform & 44.0 & 25.9 & 0 & 18.7 & 3.21 \\
Acetone & 42.5 & 16.5 & 42.5 & 8.7 & 3.61 \\
Tetrahydrofuran & 45.0 & 22.5 & 50.0 & 1.9 & 4.79 \\
Diethyl ether & 47.0 & 15.0 & 48.0 & 4.9 & 4.77 \\
\hline \#Unit free & & & & &
\end{tabular}

\section{RESULTS AND DISCUSSION}

Particle size and size distributions (PDI): The hydrodynamic radius and PDI values of the synthesized iron oxide nanoparticles were measured by DLS and represented in Table-1. As the amount of iron salts decreased from $100 \mathrm{mmol}$ to 50 mmol, average hydrodynamic radius of particles reduced from $75 \mathrm{~nm}$ to $10 \mathrm{~nm}$ but a further decrease of iron ions caused a slight increase of the radius $(20 \mathrm{~nm})$. It was reported that the particle size of the iron oxide crystals diminishes with decrease of the iron ion concentration, which is determined by X-ray diffraction, electron microscopy and vibration sample magnetometer ${ }^{43}$. However it could not be observed similar regular decrement at hydrodynamic radius, possibly due to DLS method which is affected by solution behaviour of particles. When the base concentration was raised from 1.4 to $2.8 \mathrm{M}$, the particle size fluctuated in the range of 24.3-21.6 nm. However, a further increase of the base concentration to $4.4 \mathrm{M} \mathrm{(3B)} \mathrm{brought} \mathrm{about}$ a jump in the particle size $(62.7 \mathrm{~nm})$. Besides, it was observed that the color of the precipitate transformed from black to brown. It can be said that other forms of the iron oxides (such as hematite and goethite) come into existence at high $\mathrm{pH}^{44}$. 
Dispersive component of the surface free energy $\left(\gamma_{s}{ }^{\mathrm{D}}\right)$ The dispersive surface energy $\left(\gamma_{\mathrm{s}}{ }^{\mathrm{D}}\right)$ is a very important parameter that describes ability of the material surface to establish non-polar interactions with other substances. The surface characteristics significantly influence its adhesive properties, wettability, coating ability, permeability, corrosive properties and biocompatibility.

In the first method (Schultz); a linear line was plotted for $n$-alkane solutes according to eqn. 4 as seen in Fig. 1 and $\gamma_{s}{ }^{\mathrm{D}}$ value was calculated from the slope. In the second method (Dorris and Gray); RT $\ln \mathrm{V}_{\mathrm{N}}$ against carbon numbers in $n$-alkane series was plotted as a linear line that slopes $\Delta \mathrm{G}_{\mathrm{CH}_{2}}$ at all studied temperatures as shown in Fig. 2. Thereafter, $\gamma_{s}{ }^{D}$ value was calculated using eqn. 5. Similar plots were also obtained for all temperatures and samples, but for the sake of brevity, these diagrams are not presented in this paper. Finally, all calculated $\gamma_{s}{ }^{\mathrm{D}}$ values were summarized at Table-3. It was seen that $\gamma_{\mathrm{s}}{ }^{\mathrm{D}}$ values for iron oxide nanoparticles fluctuated between 36 and $20 \mathrm{~mJ} / \mathrm{m}^{2}$ for all of the samples and temperatures. Information on the dispersive surface properties, especially the surface energy of magnetic iron oxides, is rather scarce in the literature. For iron oxides prepared by sol-gel method, $\gamma_{s}{ }^{\mathrm{D}}$ values were determined between 48 and $50 \mathrm{mj} / \mathrm{m}^{2}$ by the measurements of contact angle ${ }^{18,19}$. Batko and Voelkel ${ }^{20}$ reported higher values such as 67.5 and $65.4 \mathrm{~mJ} / \mathrm{m}^{2}$ for commercial nanohematite and nanogoethite particles by using inverse gas chromatography. In all cases, sufficient information to compare the methods and the values is lacking. However it seems that relatively low $\gamma_{s}{ }^{\mathrm{D}}$ values were obtained for iron oxide nanoparticles prepared by co-precipitation method which leads to be relatively poor crystallinity ${ }^{45}$.

With the increase of temperature, $\gamma_{s}{ }^{\mathrm{D}}$ values firstly increased and then decreased in the series of iron salts $(1 \mathrm{~K}$ $4 \mathrm{~K}$ samples) as seen in Table-3. This relation is valid for the values found from both methods. The decrease of $\gamma_{s}{ }^{\mathrm{D}}$ with temperature is expected behaviour since the adsorption is an

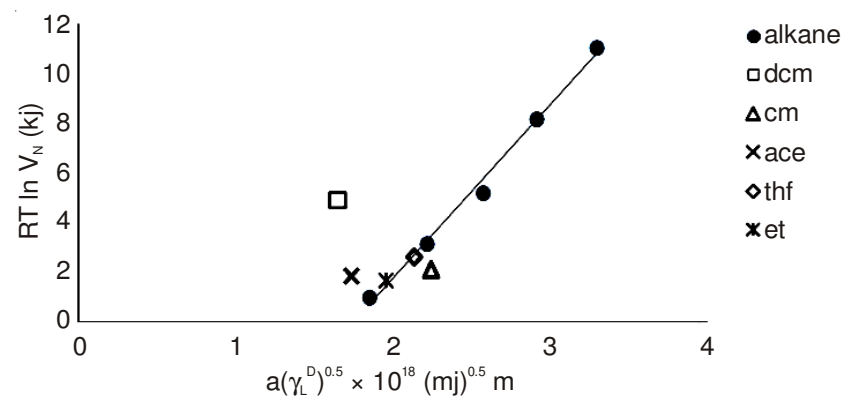

Fig. 1. Variation of $R T \ln V_{N}$ for all solutes as a function of $\alpha\left(\gamma_{L}{ }^{D}\right)^{0.5}$ on sample $4 \mathrm{~K}$ at $313 \mathrm{~K}$

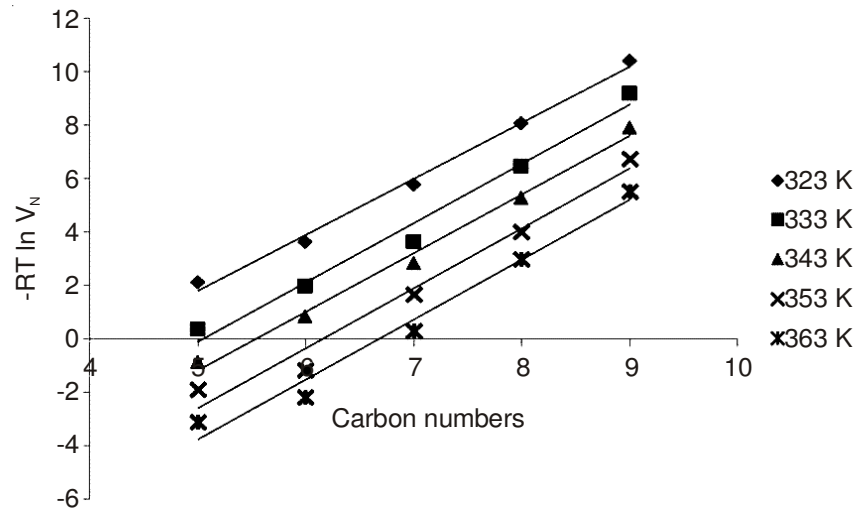

Fig. 2. Dependence of -RT $\ln V_{N}$ on carbon numbers of alkanes at the studied temperatures for the sample $3 \mathrm{~K}$

exothermic phenomenon. However, the reason of the increase of $\gamma_{\mathrm{S}}^{\mathrm{D}}$ at initial temperatures (from 313 to 333K) may be desorption of water adsorbed on the surface of iron oxide nanoparticles which makes it smoother and nearly homogeneous since smoother surface has lower dispersive energy ${ }^{23}$. It was not observed a meaningful change with temperature in the $\gamma_{s}{ }^{\mathrm{D}}$ values of the sample $3 \mathrm{~B}$ which was synthesized in the highest base concentration. The results in Table- 3 suggest that the

\begin{tabular}{|c|c|c|c|c|c|c|c|}
\hline \multicolumn{8}{|c|}{$\begin{array}{l}\text { TABLE-3 } \\
\text { DISPERSIVE SURFACE ENERGIES CALCULATED USING SCHULTZ (METHOD I) AND DORRIS-GRAY } \\
\text { (METHOD II) AND STUDIED TEMPERATURES FOR AS-PREPARED IRON OXIDE SAMPLES }\end{array}$} \\
\hline \multicolumn{4}{|c|}{$\gamma_{\mathrm{s}}^{\mathrm{D}}\left(\mathrm{mJ} / \mathrm{m}^{2}\right)$} & \multicolumn{4}{|c|}{$\gamma_{\mathrm{s}}^{\mathrm{D}}\left(\mathrm{mJ} / \mathrm{m}^{2}\right)$} \\
\hline Sample & Temperature $(\mathrm{K})$ & Method I & Method II & Sample & Temperature (K) & Method I & Method II \\
\hline \multirow{8}{*}{$4 \mathrm{~K}$} & 313 & 33.63 & 33.80 & \multirow{8}{*}{$1 \mathrm{~K}$} & 323 & 22.56 & 23.02 \\
\hline & 323 & 35.91 & 36.74 & & 333 & 26.38 & 27.42 \\
\hline & 333 & 35.51 & 36.73 & & 343 & 29.90 & 31.64 \\
\hline & 343 & 32.71 & 34.62 & & 353 & 27.87 & 23.57 \\
\hline & 353 & 30.54 & 32.88 & & 363 & 26.51 & 21.57 \\
\hline & 363 & 29.63 & 32.40 & & - & & \\
\hline & 373 & 29.28 & 32.63 & & - & & \\
\hline & 393 & 26.44 & 30.54 & & - & & \\
\hline \multirow{5}{*}{$3 \mathrm{~K}$} & 323 & 24.92 & 25.49 & \multirow{5}{*}{ 1B } & 323 & 25.58 & 26.14 \\
\hline & 333 & 29.81 & 31.03 & & 333 & 31.45 & 32.70 \\
\hline & 343 & 28.45 & 29.00 & & 343 & 26.64 & 28.08 \\
\hline & 353 & 27.11 & 23.36 & & 353 & 25.75 & 27.74 \\
\hline & 363 & 26.54 & 21.60 & & 363 & 25.15 & 27.60 \\
\hline \multirow{5}{*}{$2 \mathrm{~K}$} & 323 & 23.51 & 24.02 & \multirow{5}{*}{$3 \mathrm{~B}$} & 323 & 22.10 & 22.57 \\
\hline & 333 & 26.22 & 27.25 & & 333 & 19.88 & 20.64 \\
\hline & 343 & 26.09 & 27.07 & & 343 & 21.11 & 22.31 \\
\hline & 353 & 25.19 & 23.00 & & 353 & 20.90 & 22.46 \\
\hline & 363 & 24.17 & 22.36 & & 363 & 20.50 & 22.37 \\
\hline
\end{tabular}


dispersive surface energy of iron oxide nanoparticles increase with the iron salts concentration from $1 \mathrm{~K}$ (the lowest one) to $4 \mathrm{~K}$ (the highest one) at constant base concentration. On the other side, dispersive surface energy of iron oxide nanoparticles decreased with base concentration from $1 \mathrm{~B}$ (the lowest one) to $2 \mathrm{~K}$ and then to $3 \mathrm{~B}$ (the highest one) at constant concentration of iron salts.

For a better comparison, the values of $\gamma_{\mathrm{S}}{ }^{\mathrm{D}}$ were extrapolated to the room temperature $(293 \mathrm{~K})$ for each sample and shown in Fig. 3. It was seen obviously from the figure that dispersive surface energy increased with the concentration of iron salts but decreased with the concentration of base. In fact, the decrease of iron ion means that the amount of $\mathrm{OH}^{-}$ions increase because of reaction stoichiometry (eqn. 1). In this case, the decrease of iron salts and increase of base concentration should give the same effect. The results in the study are consistent with this comment. Consequently, it seems that the value of $\gamma_{\mathrm{S}}^{\mathrm{D}}$ depends on $\mathrm{pH}$ of the solution. However, it was reported that the poor crystallization was observed at low iron concentrations by Karaagac et al. ${ }^{43}$ which can be indicated as another reason for low dispersive surface energy. At highest base concentration (sample 3B), dispersive surface energy has the lowest value. Iron oxides are characterized by extensive polymorphism which often occurs depending on their formation $\mathrm{pH}$ values. Navrotsky ${ }^{46}$ has pointed out that there is a relation between surface energy and polymorphism in energetic of nanoparticle oxides. That is to say, the surface energy of magnetite with cubic symmetry can be changes at high $\mathrm{pH}$ value due to in the fact that its crystal structure can be transformed to goethite (orthorhombic) or hematite (rhombohedral).

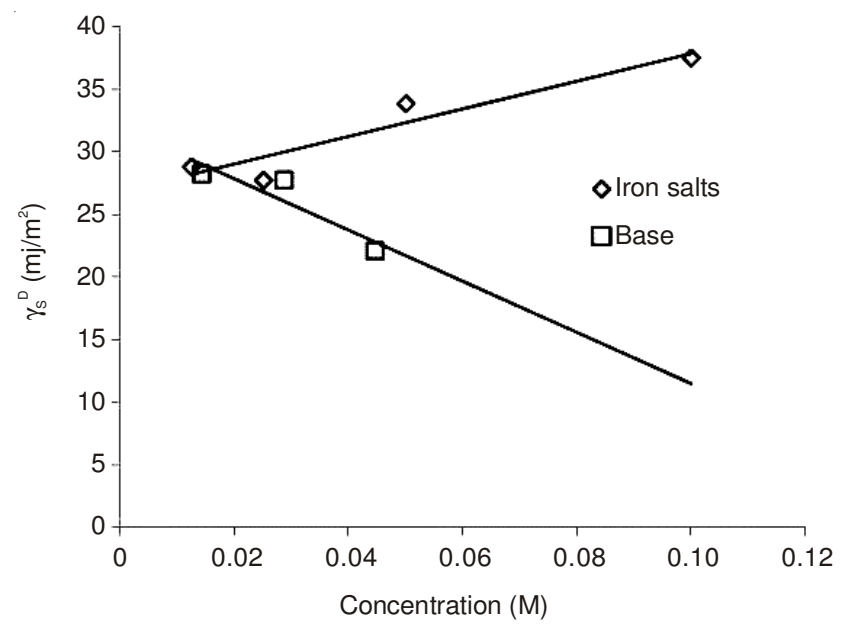

Fig. 3. Evaluation of $\gamma_{\mathrm{S}}{ }^{\mathrm{D}}$ of the samples studied at $293 \mathrm{~K}$ as a function of iron salts and base concentration (according to Schultz method)
In further investigation, we have also determined the change of enthalpy $\left(\Delta \mathrm{H}_{\mathrm{a}}\right)$ and entropy $\left(\Delta \mathrm{S}_{\mathrm{a}}\right)$ of adsorption of alkanes on the iron oxides based on eqn. 2 and 7 and summarized in Table-4. The values of enthalpy increased with chain length of alkane as expected. This rise is more pronounced for the sample $4 \mathrm{~K}$. As the iron ion concentration was decreased (from $4 \mathrm{~K}$ to $1 \mathrm{~K}$ ), $\Delta \mathrm{H}_{\mathrm{a}}$ became more negative, consequently, the interactions between alkanes and iron oxide samples became favorable significantly. This result may be explainable by the increase of amorphous site of iron oxide samples at lower iron ion amount ${ }^{43}$. Amorphous surface being larger than crystalline ones generates more favorable interaction energy. Navrotsky $^{46}$ also showed that amorphous structures have higher enthalpy than the stable well-crystallized forms.

The increase of base concentration (1B, 2K, 3B) slightly influenced the adsorption enthalpy of the iron oxide nanoparticles. A noteworthy result in the base series is that like dispersive surface energies, the adsorption enthalpy of the sample $3 \mathrm{~B}$ is smaller than those of $1 \mathrm{~B}$ and $2 \mathrm{~K}$. These results indicate that different surface properties appear at high $\mathrm{pH}^{44}$.

Considering the entropy values of alkanes at Table-4, there is a regular rise as the amount of iron ion decrease from 100 $\mathrm{mmol}$ to $12.5 \mathrm{mmol}$. It is probably due to the increase of degree of freedom at expanded surface as a result of rich amorphous segment on the surfaces of iron ion poor samples like $1 \mathrm{~K}$.

Free enthalpy, $\Delta G^{S P}$, enthalpy; $\Delta H^{\mathrm{SP}}$ and entropy; $\Delta S^{\mathrm{SP}}$ of specific adsorption: The free enthalpy of specific adsorption was estimated according to eqn. 6 using topology indices $\left(\chi_{\mathrm{t}}\right)$ of alkanes and polar solutes at Table-2. The $\chi_{\mathrm{t}}$ is an extension of Wiener's index, for molecules containing heteroatoms, considering bond lengths, number of electrons of atoms ${ }^{34,47}$. The variation of the free enthalpy of adsorption with respect to ct for the sample 3 at $323 \mathrm{~K}$ is given as an example in Fig. 4.

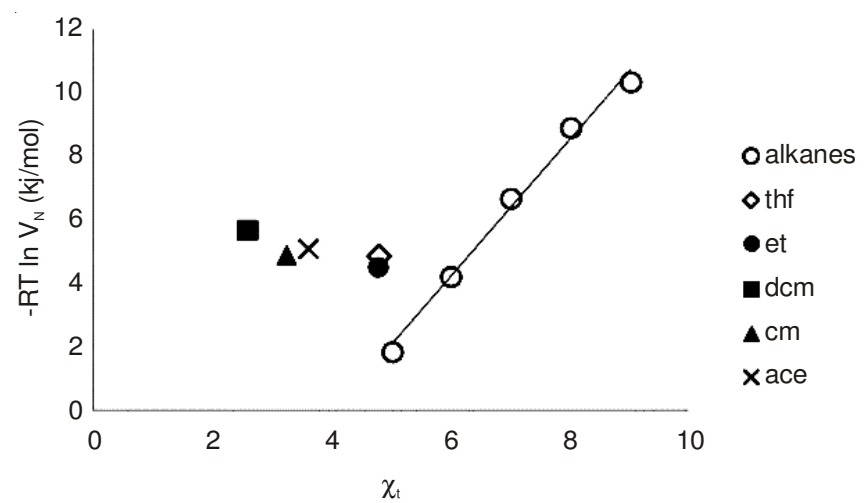

Fig. 4. Variation of $\Delta \mathrm{G}_{\mathrm{a}}$ as a function $\chi_{\mathrm{t}}$ for all solutes on the sample $3 \mathrm{~K}$ at $323 \mathrm{~K}$

TABLE-4

ENTHALPIES AND ENTROPIES OF THE ADSORPTION OF ALKANES ON IRON OXIDE SAMPLES

\begin{tabular}{cccccc|ccccc}
\hline \multicolumn{9}{c}{$\Delta \mathrm{H}_{\mathrm{a}}\left(\mathrm{kJmol}^{-1}\right)$} & & \multicolumn{4}{c}{$\Delta \mathrm{S}_{\mathrm{a}}\left(\mathrm{Jmol}^{-1} \mathrm{~K}^{-1}\right)$} \\
\hline Sample & Pen & Hex & Hep & Oct & Non & Pen & Hex & Hep & Oct & Non \\
\hline 4K & -26.7 & -35.5 & -36.6 & -42.2 & -45.5 & 86.4 & 92.0 & 103.8 & 113.1 & 122.9 \\
3K & -31.5 & -43.3 & -47.3 & -48.1 & -48.7 & 91.7 & 121.2 & 124.7 & 125.8 & 126.9 \\
2K & -43.3 & -46.3 & -47.3 & -48.8 & -52.7 & 128.1 & 128.6 & 129.6 & 136.3 & 141.6 \\
1K & -44.6 & -50.6 & -51.1 & -52.8 & -53.9 & 132.0 & 137.1 & 140.6 & 142.4 & 147.9 \\
1B & -42.6 & -46.4 & -48.3 & -49.4 & -50.5 & 126.0 & 128.6 & 131.6 & 132.5 & 133.9 \\
3B & -39.9 & -40.3 & -41.7 & -47.8 & -48.0 & 114.2 & 116.0 & 118.4 & 120.2 & 124.1 \\
\hline
\end{tabular}


The free enthalpies of specific adsorption of polar solutes on the iron oxide samples are presented in Fig. 5 at 333K. The highest $\Delta \mathrm{G}^{\mathrm{SP}}$ values were observed with Lewis acids such as dichloromethane and chloroform however the lowest $\Delta \mathrm{G}^{\mathrm{SP}}$ values was were observed with Lewis bases such as tetrahydrofuran and diethyl ether. This suggests that the adsorption sites on the surface of iron oxide are basic for all of the samples. Besides, the values of $\Delta \mathrm{G}^{\mathrm{SP}}$ of acetone with amphoteric nature were found very close to acidic chloroform but higher than those of basic solutes. It seems that acetone behaves like an acid towards to basic iron oxide surface.

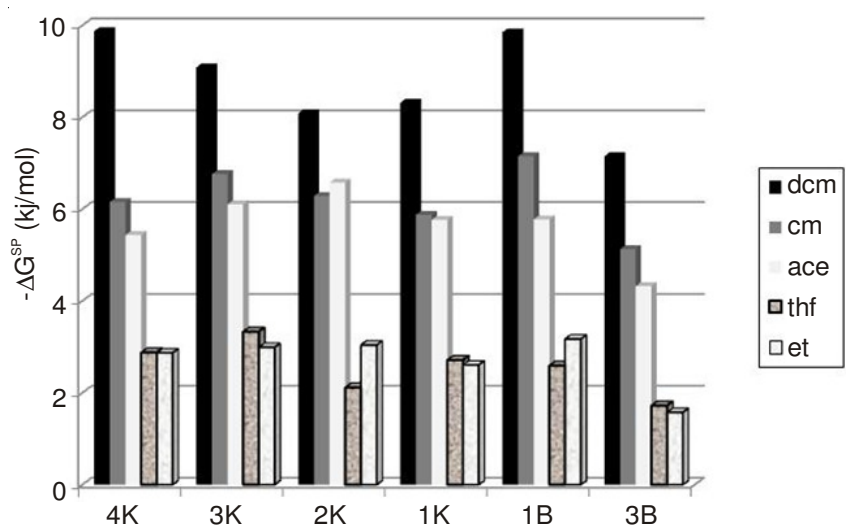

Fig. 5. Free enthalpies of specific adsorption of polar solutes on the iron oxide samples at $333 \mathrm{~K}$

In comparison of the samples, $4 \mathrm{~K}$ and $1 \mathrm{~B}$ have the higher $\Delta \mathrm{G}^{\mathrm{SP}}$ values for dichloromethane according to Fig. 5. This effect may be due to iron ions adsorbed on the surface of nanoparticles because both of samples includes higher iron/hydroxide mol rate. For a better investigation, the free enthalpies of specific adsorption of dichloromethane were scaled to initial mol ratio of $\mathrm{Fe}_{(\mathrm{tot})} / \mathrm{OH}$ in Fig. 6. Indeed, the figure exhibited that there was a linear correlation between $\Delta \mathrm{G}^{\mathrm{SP}}$ and the iron/ hydroxide mol rate at $323 \mathrm{~K}$. However this correlation distorted with temperature since the free enthalpy of $4 \mathrm{~K}$ decreased more than others. It also was found a similar relationship for chloroform solute. But the reduction in $\Delta \mathrm{G}^{\mathrm{SP}}$ of chloroform solute with temperature was not as much as that of dichloromethane. (see Fig. 7). Consequently, it can be assumed that there is a specific interaction between $\mathrm{Cl}$ atoms in both of dichloromethane and chloroform molecules and $\mathrm{Fe}$ atoms on particle surface that could not be removed by the washing at high iron concentrations. It seems that higher $\Delta \mathrm{G}^{\mathrm{SP}}$ values belonging to dichloromethane with nanoparticles may indicate adsorption of metallic entities on a solid surface.

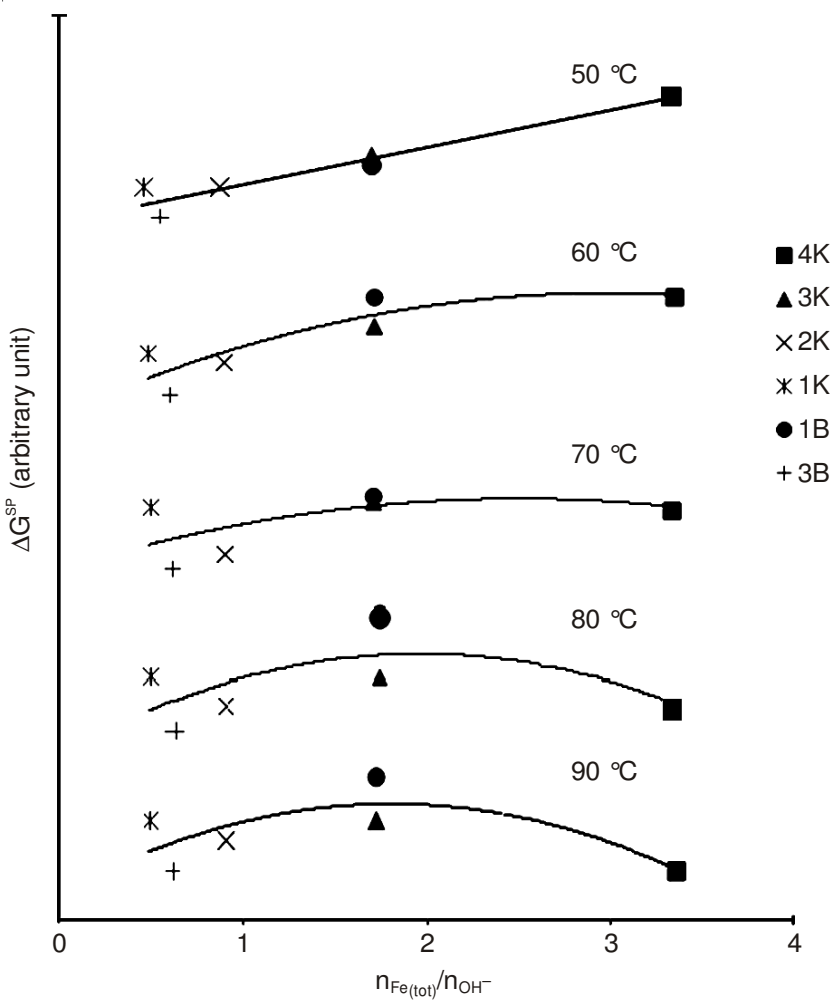

Fig. 6. Variation of $\Delta \mathrm{G}^{\mathrm{SP}}$ values arising from the specific interactions of dichloromethane with the nanoparticle samples against initial $\mathrm{Fe}_{(\text {total }} /$ $\mathrm{OH}$ mol ratio in the synthesis at the studied temperatures

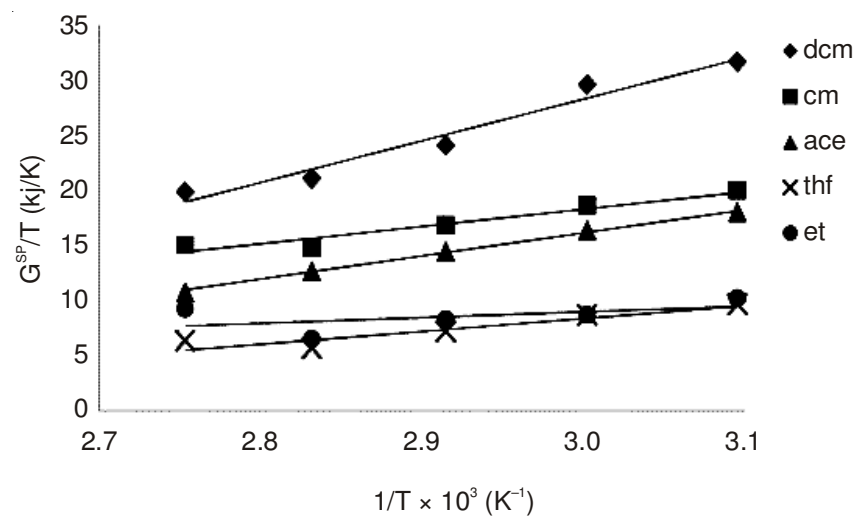

Fig. 7. Evaluation of specific enthalpies and entropies of adsorption according to eqn. 7 by plotting $\Delta \mathrm{G}^{\mathrm{SP}} / \mathrm{T}$ versus $1 / \mathrm{T}$ for the sample $4 \mathrm{~K}$

Plotting $\Delta \mathrm{G}^{\mathrm{SP}}$ of the polar solutes as a function of temperature in Fig. 7, the specific enthalpy, $\Delta \mathrm{H}^{\mathrm{SP}}$ and the specific entropy, $\Delta S^{\mathrm{SP}}$ were determined by using eqn. 7 and summarized in Table-5.

\begin{tabular}{|c|c|c|c|c|c|c|c|c|c|c|c|c|}
\hline \multicolumn{13}{|c|}{$\begin{array}{c}\text { TABLE-5 } \\
\text { SPECIFIC ADSORPTION ENTHALPY AND ENTROPY OF INTERACTIONS } \\
\text { BETWEEN THE IRON OXIDE SAMPLES AND POLAR SOLUTE }\end{array}$} \\
\hline \multicolumn{7}{|c|}{$-\Delta \mathrm{H}^{\mathrm{SP}}\left(\mathrm{kJ} \mathrm{mol}^{-1}\right)$} & \multicolumn{6}{|c|}{$\Delta \mathrm{S}^{\mathrm{SP}}\left(\mathrm{kJ} \mathrm{mol}^{-1} \mathrm{~K}^{-1}\right)$} \\
\hline Solute & $4 K$ & $3 \mathrm{~K}$ & $2 \mathrm{~K}$ & $1 \mathrm{~K}$ & $1 \mathrm{~B}$ & $3 B$ & $4 \mathrm{~K}$ & $3 \mathrm{~K}$ & $2 \mathrm{~K}$ & $1 \mathrm{~K}$ & $1 \mathrm{~B}$ & $3 B$ \\
\hline Dcm & 37.6 & 15.9 & 15.1 & 15.5 & 10.1 & 13.0 & 2.3 & 1.5 & 1.5 & 1.6 & 1.7 & 1.4 \\
\hline $\mathrm{Cm}$ & 16.0 & 19.1 & 15.7 & 17.0 & 9.8 & 9.6 & 1.9 & 2.1 & 1.9 & 2.1 & 1.6 & 1.5 \\
\hline Ace & 21.2 & 8.6 & 8.2 & 8.4 & 6.4 & 7.4 & 2.2 & 0.9 & 0.8 & 1.3 & 1.6 & 1.4 \\
\hline Thf & 15.6 & 10.5 & 8.7 & 8.4 & 8.1 & 5.7 & 2.5 & 2.0 & 2.4 & 2.1 & 2.1 & 2.1 \\
\hline Et & 12.9 & 7.5 & 7.2 & 3.6 & 5.3 & 3.8 & 2.4 & 2.0 & 2.1 & 1.4 & 1.9 & 1.7 \\
\hline
\end{tabular}


Comparison of the values obtained for $-\Delta \mathrm{H}^{\mathrm{SP}}$ in Table-5 depicts that the values of $-\Delta \mathrm{H}^{\mathrm{SP}}$ of $1 \mathrm{~K}$ sample which has highest iron concentration considerably are higher than those of others. This means that the favorable interaction between solutes and the sample becomes high as iron amount in the synthesis solution increases. The specific adsorption enthalpies of tetrahydrofuran and ether with basic nature reduced linearly with a decrease of amount of iron salts however those of acidic ones did not show a similar correlation. Furthermore $-\Delta \mathrm{H}^{\mathrm{SP}}$ of dichloromethane was found considerably higher than that of chloroform although its acceptor number is smaller as shown in Table-2. This can be explained that dichloromethane molecules which have higher orientation polarization than that of chloroform can settle down more densely on particle surface due to $\mathrm{Fe}$ ions which have vacillating valence electrons, which results in longer retention time and higher exothermic adsorption energy.

Table- 5 also demonstrates that the values of specific entropy of the samples were not changed dramatically as a function of the concentration of the iron salts and the base.

Acid-base properties: Acceptor and donor interaction parameters or acid and base constants $\left(\mathrm{K}_{\mathrm{A}}\right.$ and $\left.\mathrm{K}_{\mathrm{D}}\right)$ of the iron oxide nanoparticles were obtained for a more complete evaluation of iron oxide acid-base properties. These parameters are determined according to eqn. 8 based on the relation between enthalpy of specific adsorption and both donor and acceptor numbers of applied polar solutes. In Fig. 8, examples of graphics used to determine $\mathrm{K}_{\mathrm{A}}$ and $\mathrm{K}_{\mathrm{D}}$ were presented and the values obtained for each sample were summarized at Table6. We have also given the acid and base constants of the samples determined by using two other methods based on the surface $\operatorname{are}^{26,39,48,49}$ and the vapor pressure ${ }^{30,50}$ of the solutes at Table- 6 .
Although the found values of $K_{D}$ and $K_{A}$ of the samples are somewhat different for three methods, the values of $\mathrm{K}_{\mathrm{D}} / \mathrm{K}_{\mathrm{A}}$ are in the same scale and consistent with each other. It is very well known that iron oxides have basic nature. However we have found that their basic character $\left(\mathrm{K}_{\mathrm{D}} / \mathrm{K}_{\mathrm{A}}\right)$ changes depending on the synthesis parameters of co-precipitation method. Table-6 indicates that basic character of the iron oxide nanoparticles increases with base concentration and decreases with iron salt concentration. As an exception, $4 \mathrm{~K}$ has showed highly basic character although its base concentration is not highest among the samples. As stated earlier, this may be a result of an extra interaction between $\mathrm{Cl}$ and $\mathrm{Fe}$ atoms accompanied to common Lewis acid-base interactions, thus $\mathrm{K}_{\mathrm{D}}$ is obtained higher than expected.

\section{Conclusion}

The surface modification of magnetic iron oxides is very important, because it may improve both the colloidal and physical stability of the particles, increase their water-dispersibility and provide functionalization for further conjugation with bioactive molecules or targeting ligands. Frequently, such modifications are carried out in the solution medium shortly after the synthesis of the iron oxide nanoparticles by co-precipitation. This study showed that more effective surface modifications can be done adjusting the synthesis variables of the co-precipitation. Besides, the usefulness of inverse gas chromatography for identifying differences in the adsorption properties of iron oxides was also demonstrated. The method appears quite sensitive to the changes in surface energy that results from different synthesis conditions.

The values of dispersive surface energy, $\gamma_{s}^{\mathrm{D}}$, reduced with the base concentration but increased with the iron salts
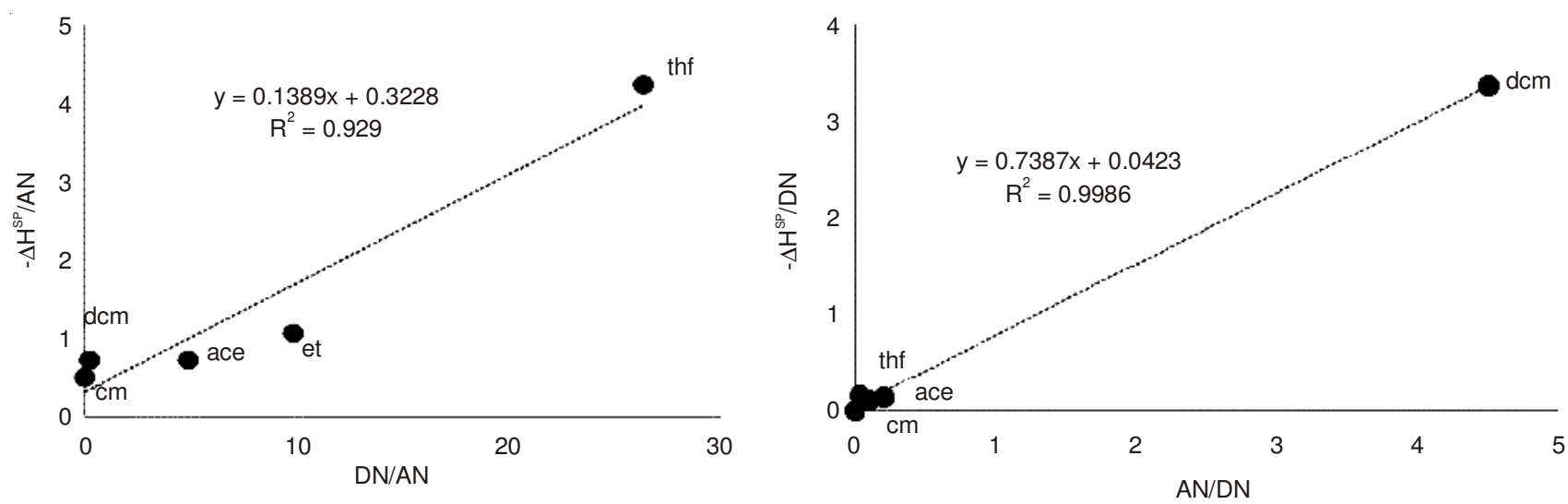

Fig. 8. Correlations between specific enthalpies $\Delta \mathrm{H}^{\mathrm{SP}}$ of adsorption of the chosen solutes and the DN and AN values of these solutes according to eqn. 8

TABLE-6

ACID-BASE CONSTANTS $\left(\mathrm{K}_{\mathrm{A}}\right.$ AND $\mathrm{K}_{\mathrm{D}}$ ) CALCULATED ACCORDING TO TOPOLOGY INDICES, VAPOR PRESSURE AND SURFACE AREA OF THE POLAR SOLUTES FOR THE IRON OXIDE NANOPARTICLES

\begin{tabular}{cccc|ccc|cccc}
\hline \multirow{2}{*}{ Property } & \multicolumn{3}{c}{ Topology indices } & \multicolumn{3}{c|}{ Vapor pressure } & \multicolumn{3}{c}{ Surface area } \\
\cline { 2 - 10 } & $\mathrm{K}_{\mathrm{A}}$ & $\mathrm{K}_{\mathrm{D}}$ & $\mathrm{K}_{\mathrm{D}} / \mathrm{K}_{\mathrm{A}}$ & $\mathrm{K}_{\mathrm{A}}$ & $\mathrm{K}_{\mathrm{D}}$ & $\mathrm{K}_{\mathrm{D}} / \mathrm{K}_{\mathrm{A}}$ & $\mathrm{K}_{\mathrm{A}}$ & $\mathrm{K}_{\mathrm{D}}$ & $\mathrm{K}_{\mathrm{D}} / \mathrm{K}_{\mathrm{A}}$ \\
\hline $4 \mathrm{~K}$ & 0.24 & 2.78 & 11.43 & 0.15 & 1.77 & 12.21 & 0.16 & 2.09 & 12.86 \\
$3 \mathrm{~K}$ & 0.17 & 1.17 & 6.78 & 0.09 & 0.44 & 4.82 & 0.10 & 0.62 & 6.22 \\
$2 \mathrm{~K}$ & 0.14 & 1.11 & 7.98 & 0.12 & 0.82 & 6.68 & 0.13 & 0.96 & 7.43 \\
$1 \mathrm{~K}$ & 0.13 & 1.15 & 8.82 & 0.08 & 0.59 & 7.15 & 0.09 & 0.81 & 8.55 \\
$1 \mathrm{~B}$ & 0.14 & 0.74 & 5.32 & 0.04 & 0.14 & 3.19 & 0.04 & 0.14 & 3.18 \\
$3 \mathrm{~B}$ & 0.08 & 0.96 & 11.35 & 0.04 & 0.44 & 10.87 & 0.05 & 0.63 & 12.63 \\
\hline
\end{tabular}


concentrations. It was found that the interactions between alkanes and iron oxide samples can become favourable with the increase of amorphous site of iron oxide samples at lower iron ion amount. This result can open a new research field on determination of crystallinity of inorganic particles by inverse gas chromatography, like polymers ${ }^{51,52}$. As expected, the iron oxide nanoparticles are of basic character by increasing with base concentration but decreasing with iron salt concentration. Additionally, the sample with highest iron concentration did not comply with this trend because of the extra interactions between $\mathrm{Fe}$ and $\mathrm{Cl}$ atoms which leads to bigger $\mathrm{K}_{\mathrm{D}}$.

\section{ACKNOWLEDGEMENTS}

This work was supported by TUBITAK Post-doctorate Fellowship Programme.

\section{REFERENCES}

1. S. Laurent, D. Forge, M. Port, A. Roch, C. Robic, L. Vander Elst and R.N. Muller, Chem. Rev., 108, 2064 (2008).

2. A.S. Teja and P. Koh, Prog. Cryst. Growth Charact. Mater., 55, 22 (2009).

3. L.H. Reddy, J.L. Arias, J. Nicolas and P. Couvreur, Chem. Rev., 112, 5818 (2012).

4. C.G.C.M. Netto, H.E. Toma and L.H. Andrade, J. Mol. Catal. B, 85-86, 71 (2013).

5. F.M. Kievit and M. Zhang, Acc. Chem. Res., 44, 853 (2011).

6. A.K. Gupta and M. Gupta, Biomaterials, 26, 3995 (2005).

7. N.T.K. Thanh and L.A.W. Green, Nano Today, 5, 213 (2010).

8. D.K. Kim, M. Mikhaylova, Y. Zhang and M. Muhammed, Chem. Mater., 15, 1617 (2003).

9. A.S. Lubbe, C. Alexiou and C. Bergemann, J. Surg. Res., 95, 200 (2001).

10. B. Grzeta, M. Ristic, I. Nowik and S. Music, J. Alloys Comp., 334, 304 (2002).

11. H. Itoh and T. Sugimoto, J. Colloid Interf. Sci., 265, 283 (2003).

12. Y. Lee, J. Lee, C.J. Bae, J.G. Park, H.J. Noh, J.H. Park and T. Hyeon, Adv. Funct. Mater., 15, 503 (2005).

13. R. Massart, IEEE Trans. Magn., 17, 1247 (1981).

14. P. Xu, G.M. Zeng, D.L. Huang, C.L. Feng, S. Hu, M.H. Zhao, C. Lai, Z. Wei, C. Huang, G.X. Xie and Z.F. Liu, Sci. Total Environ., 424, 1 (2012).

15. S. Laurent, D. Forge, M. Port, A. Roch, C. Robic, L. Vander Elst and R.N. Muller, Chem. Rev., 108, 2064 (2008).

16. P. Roonasi, Licentiate thesis, Adsorption and Surface Reaction Properties of Synthesized Magnetite Nano-Particles, Luleå University of Technology, Sweden (2007).

17. Z.X. Sun, F.W. Su, W. Forsling and P.O. Samskog, J. Colloid Interf. Sci., 197, 151 (1998).

18. J.L. Arias, V. Gallardo, F. Linares-Molinero and A.V. Delgado, J. Colloid Interf. Sci., 299, 599 (2006).
19. J.L. Arias, V. Gallardo, S.A. Gómez-Lopera, R.C. Plaza and A.V. Delgado, J. Control. Rel., 77, 309 (2001).

20. K. Batko and A. Voelkel, J. Colloid Interf. Sci., 315, 768 (2007).

21. G.C.C. Costa, S.V. Ushakov, R.H.R. Castro, A. Navrotsky and R. Muccillo, Chem. Mater, 22, 2937 (2010).

22. R.J. Good, J. Adhes. Sci. Technol., 6, 1269 (1992).

23. C. Sun and J.C. Berg, J. Chromatogr. A, 969, 59 (2002).

24. T. Hamieh, M.-B. Fadlallah and J. Schultz, J. Chromatogr. A, 969, 37 (2002).

25. S. Kubilay, R. Gurkan, A. Savran and Z. Yalcinkaya, Colloid J., 68, 274 (2006)

26. Y.C. Yang and P.R. Yoon, J. Korean Chem. Eng., 24, 451 (2007).

27. D. Steven Keller and P. Luner, Colloids Surf. A, 161, 401 (2000).

28. P. Schmitt, E. Koerper, J. Schultz and E. Papirer, Chromatographia, 25, 786 (1988)

29. J.-B. Donnet, H. Balard, N. Nedjari, B. Hamdi, H. Barthel and T. Gottschalk-Gaudig, J. Colloid Interf. Sci., 328, 15 (2008).

30. A. Voelkel and T. Grzes'kowiak, J. Mater. Chem., 11, 1288 (2001).

31. T. Hamieh, M. Nardin, M. Rageul-Lescouët, H. Haïdara and J. Schultz, Colloids Surf. A, 125, 155 (1997).

32. M. Przybyszewska, A. Krzywania, M. Zaborski and M.I. Szynkowska, J. Chromatogr. A, 1216, 5284 (2009).

33. E. Brendlé, J. Dentzer and E. Papirer, J. Colloid Interf. Sci., 199, 63 (1998).

34. E. Brendle' and E. Papirer, J. Colloid Interf. Sci., 194, 207 (1997)

35. S.K. Milonji'c, Mater. Manuf. Process., 24, 1086 (2009).

36. J. Tang, M. Myers, K.A. Bosnick and L.E. Brus, J. Phys. Chem. B, 107, 7501 (2003).

37. J.M.R.C.A. Santos and J.T. Guthrie, Mater. Sci. Eng. Rep., 50, 79 (2005).

38. F.M. Fowkes, J. Adhes. Sci. Technol., 1, 7 (1987).

39. J. Schultz, L. Lavielle and C. Martin, J. Adhes., 23, 45 (1987).

40. G.M. Dorris and D.G. Gray, J. Colloid Interf. Sci., 77, 353 (1980).

41. R.J. Drago, G.C. Vogel and T.E. Needham, J. Am. Chem. Soc., 93, 6014 (1971).

42. E. Brendle and E. Papirer, Powders and Fibres-Interfacial Science and Applications, Surfactant Science Series, CRC Press, Boca Raton, FL, vol. 137, p. 50 (2007).

43. O. Karaagac, H. Kockar, S. Beyaz and T. Tanrisever, IEEE Trans. Magn., 46, 3978 (2010).

44. U. Schwertmann and E. Murad, Clays Clay Miner., 31, 277 (1983).

45. T. Iwasaki, K. Kosaka, N. Mizutani, S. Watano, T. Yanagida, H. Tanaka and T. Kawai, Mater. Lett., 62, 4155 (2008).

46. A. Navrotsky, Geochem. Trans., 4, 34 (2003).

47. E. Brendle and E. Papirer, J. Colloid Interf. Sci., 194, 217 (1997).

48. N.E. Moustafa and D.S. El-Desouki, Chem. Paper, 63, 371 (2009).

49. D. Topaloglu Yazici, A. Askin and V. Bütün, Surf. Interface Anal., 38, 561 (2006).

50. C. Saint Flour and E. Papirer, J. Colloid Interf. Sci., 91, 69 (1983).

51. C.T. Chen and Z.Y. Al-Saigh, Macromolecules, 22, 2974 (1989).

52. O. Yazici, F. Cakar, O. Cankurtaran and F. Karaman, J. Appl. Polym. Sci., 113, 901 (2009). 